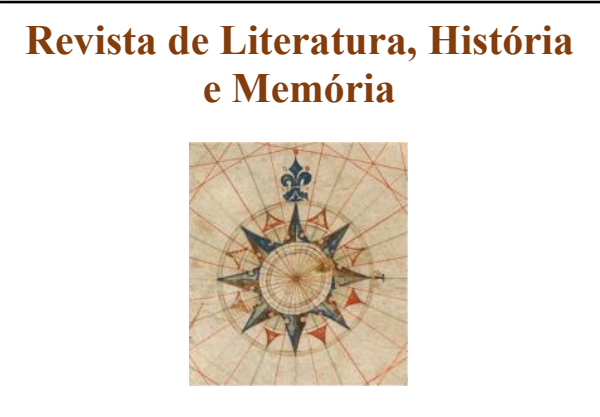

Dossiê: Manifestações de re-existência: a literatura em tempos de repressão

ISSN 1983-1498

VOL. 16 - No 27 - 2020

U N I O E S T E / CA S CA V E L - p. 116-140

\title{
PROJEÇÕES APOCALÍPTICAS E ANTI-DISTOPIA NA OBRA DE TORQUATO NETO (1968-1972)
}

\author{
Apocalyptic projections and anti-dystopia in Torquato \\ Neto's work (1968-1972)
}

\author{
Luis Gustavo de Paiva Faria ${ }^{1}$ \\ Victor Luiz Alves Mourão ${ }^{2}$
}

RESUMO: O objetivo do trabalho é analisar a produção literária e jornalística de Torquato Neto entre 1968 e 1972, enfocando um corpus delimitado de poemas e canções e a coluna Geléia Geral (1971-1972). Sustenta-se que a produção do autor expõe figurações históricas e poéticas que oscilam por meio de caracterizações utópicas, distópicas, heterotópicas e antidistópicas, particularmente marcadas pela presença repetida do vocábulo "fim", alternando em um espectro que vai da projeção de realidades fabulosas (utopia) à luta pela criação de espaços de resistência e contestação (anti-distopia). Considerando a mediação de seu contexto histórico, coloca-se a hipótese de que as produções artísticas deste período não podem ser entendidas de maneira homogênea, precipitando-se como exclusivamente utópicas (escapistas) ou distópicas (fatalistas), mas consideradas em sua pluralidade, sobretudo em seus esforços antidistópicos, ou seja, práticas que procuram forjar espaços de liberdade em meio à repressão da ditadura militar brasileira.

PALAVRAS-CHAVE: Torquato Neto. Ditadura Militar. Anti-distopia.

ABSTRACT: This paper aims to analyze Torquato Neto's literary and journalistic production between 1968 and 1972, focusing on a delimited corpus of poems and songs and the column Geléia Geral (1971-1972). It is argued that the author's production exposes poetical figurationsthat oscillates between utopian, dystopian, heterotopic and anti-dystopian characterizations, particularly marked by the repeated presence of the word "end", alternating in a spectrum from the projection of invented realities (utopia) to the struggle for the creation of spaces of political and aesthetic resistance (antidystopia). Considering the mediation of historical context, it is hypothesized that the artistic productions of this period cannot be understood in a homogeneous way, precipitating as exclusively utopian (escapists) or dystopian (fatalistic), but that their plurality should be considered, especially their anti-dystopian efforts; that is, practices that seek to forge spaces of freedom amid the repression of the Brazilian military dictatorship.

KEYWORDS: Torquato Neto. Military Dictatorship. Anti-dystopia.

\section{INTRODUÇÃO}

Aqui é o fim do mundo. Assim é o único verso do refrão de Marginália II (1968), composição de Torquato Neto e Gilberto Gil presente no segundo álbum do músico baiano.

\footnotetext{
1 Mestrando em Estudos Literários pela Universidade Federal de Viçosa (PPGLET/UFV). Bacharel e Licenciado em Ciências Sociais pela mesma instituição. Contato: lgpaivafaria@gmail.com.

2 Professor Adjunto do Departamento de Ciências Sociais da Universidade Federal de Viçosa (DCS/UFV). Doutor em Sociologia pelo Programa de Pós-graduação em Sociologia do Instituto de Estudos Sociais e Políticos (IESP-UERJ). Contato: vmourao@ufv.br.
} 
Além de clássico tropicalista, a canção antecipa, como em um prenúncio apocalíptico, o Ato Institucional n. 5 (AI-5), assinado oficialmente em 13 de dezembro de 1968, sete meses após o lançamento do álbum de Gilberto Gil. Conhecido como os "anos de chumbo" (1968-1974) da ditadura militar brasileira, o período foi caracterizado por forte censura aos meios de comunicação e às produções artísticas de oposição, bem como forte repressão aos grupos sociais de contestação ao regime, como universitários e militantes de partidos de esquerda.

A existência de um cenário autoritário e repressivo ${ }^{3}$, associado à experiência de sujeitos de determinados grupos sociais, foi e ainda tem sido fartamente documentada por historiadores. Ferrer (2011) organizou uma série de relatos de pessoas que sofreram, de diferentes modos, as consequências deste contexto, vinculando-as ao que chamou de Geração de 68. Em um dos relatos, Tânia Marins Roque fala sobre as consequências do AI-5 para militantes daquele período: "Em 1969, o número de prisões ilegais e arbitrárias aumenta, incluindo a minha [...].O clima de terror, as denúncias, as desconfianças, os estouros de aparelhos, as prisões constituíam o cotidiano" (FERRER, 2011, p. 119-126). Esse cenário repressivo também é vivenciado pela classe artístico-intelectual que fazia oposição ao regime ou buscava manter algum nível de autonomia em suas atividades profissionais. Ao contrário, o AI-5 acentua a repressão aos intelectuais e aos artistas, levando ao exílio de Chico Buarque, Gilberto Gil, Caetano Veloso, Ferreira Gullar e diversos outros nomes.

Em 1969, após uma viagem à Inglaterra e à França, Torquato Neto, poeta tropicalista e jornalista experimental, retorna ao Brasil em plena vigência do AI-5 e recrudescimento da censura $^{4}$. Apesar das adversidades impostas, o autor assina um contrato temporário como articulista do jornal Última Hora, iniciando a clássica coluna Geléia Geral, um espaço em que, além de críticas e comentários ao cinema e à música nacionais e internacionais, o autor faz reflexões e digressões sobre temas diversificados, construindo um privilegiado espaço de questionamentos e críticas àquela realidade autoritária. Paralelamente à atividade jornalística, o autor dá continuidade às suas produções literárias, musicais e cinematográficas, dentre as

\footnotetext{
${ }^{3}$ É importante observar que esse cenário de repressão e censura não é generalizado para a toda a população brasileira, mas para segmentos sociais específicos, especialmente aqueles críticos ao regime militar. Não são incomuns os registros históricos que apresentam relatos de indivíduos que não "viveram uma experiência" ditatorial, o que, contudo, não dá validade à afirmação de que não houve repressão ou que apenas aqueles que moral ou politicamente "errados" (geralmente chamados de "subversivos") a sofreram. Diversos grupos foram perseguidos em um ambiente de explícita repressão, como indicam os relatos organizados por Ferrer (2011) e os dados elencados por Ridenti (2010). Para mais informações sobre esse período e as ações e instituições de repressão, consultar os relatórios produzidos pela Comissão Nacional da Verdade, disponíveis em http://cnv.memoriasreveladas.gov.br/, acesso em 10 de outubro de 2019.

${ }^{4}$ Nesse momento, o autor afasta-se do núcleo tropicalista, do qual foi um dos fundadores, e aproxima-se do concretismo e do Cinema Marginal, bem como de outras personalidades artísticas, como Ivan Cardoso, Hélio Oiticica e Waly Salomão. É notável, desse modo, sua múltipla associação a movimentos artísticos críticos à ditadura militar ao longo de sua trajetória.
} 
quais consta a publicação do volume póstumo Os Últimos Dias de Paupéria (1973), organizado pelo poeta Waly Salomão.

Ainda que seja um grave equívoco tomar sua obra como reflexo do contexto histórico, seria um erro ignorar a experiência da ditadura como marco histórico que, associada a fatos biográficos e posicionamentos estéticos, constituem influências e substratos para suas figurações poéticas. Em Torquato Neto, a dialética entre ficção e realidade precipita-se em fragmentos de universos ficcionais que não raramente assumem tom apocalíptico diante das possibilidades e "ciladas" da realidade e da própria literatura. Se a ditadura militar não foi uma distopia, talvez para Torquato Neto o tenha sido. Ou quase isso.

O objetivo deste trabalho é analisar a produção literária e jornalística de Torquato Neto entre 1968 e 1972, enfocando um corpus delimitado de poemas e canções e a coluna Geléia Geral (1971-1972), em que busca-se articular as criações e os experimentos de sua obra poética e jornalística. Sustenta-se a hipótese de que a produção do autor expõe figurações poéticas que oscilam por meio de caracterizações utópicas, distópicas, heterotópicas e antidistópicas (CLAYES, 1999, 2017; FOUCAULT, 2003), particularmente marcadas pela presença repetida do vocábulo "fim" e pela vinculação deste às categorias de espaço e tempo, alternando em um retalhado espectro que vai da projeção de realidades fabulosas (utopia) à luta pela criação de espaços de resistência e contestação (anti-distopia).

Para tanto, o trabalho foi dividido em três seções, além desta introdução e das considerações finais. Na primeira, articula-se teoricamente os conceitos de utopia, distopia, heterotopia e anti-distopia, dedicando-se a lançar o que seriam as bases e os pressupostos desta última categoria. A segunda parte dedica-se a explorar a obra poética de Torquato Neto, justificando a presença de "projeções e sensações apocalípticas" em sua obra a partir de análise de um corpus delimitado de sua poesia e seu cancioneiro. A terceira, por fim, articula trechos de sua coluna Geléia Geral e de suas correspondências para pensá-las a partir do conceito de anti-distopia, expandindo, assim, as possibilidades conceituais de práticas discursivas de resistência ao autoritarismo e à repressão da ditadura militar brasileira.

\section{OSCILAÇÕES ESPAÇO-TEMPORAIS: SOBRE CATEGORIAS E CONCEITOS}

A discussão sobre a utopia no âmbito da reflexão cultural e literária possui uma trajetória que não pretende ser abarcada aqui de maneira exaustiva. A fim de explorar elementos conceituais, chama-se a atenção para o caráter espacial da noção, ora apontando para um lugar inexistente (u-tópico), ora para um bom lugar (eu-tópico) e, como marca 
relativamente mais recente da nossa experiência moderna, ora para um mau lugar (dis-tópico) (CLAEYS, SARGENT, 1999; MATOS, 2017; CLAEYS, 2017). Se é possível traçar construções utópicas desde a Grécia Antiga em Hesíodo (CLAEYS, SARGENT, 1999), foi com a emergência de uma vaga humanista na virada para o século XVI que o termo passou a sintetizar as referências a um "não lugar em tempo algum" (MORE, 2017; JÚNIOR, 2017, p. 13). Tal movimento permitiu à produção literária uma imaginação social (social dreaming) que se tornou uma espécie de reflexo das mudanças paradigmáticas no âmbito cultural. Assim, essa liberação da produção textual e literária para alcançar e produzir lugares e povos imaginários não sinalizou, no entanto, uma descolagem completa das formações históricas, intelectuais e políticas dos seus contextos.

A partir da compilação de textos utópicos feita por Claeys (1999), é possível identificar diferentes vagas históricas de textos utópicos que se seguiram à original produção moreana: uma, situada a partir do século XVI, com conotações religiosas radicais, buscando esquemas igualitários espartanos e cristão-monásticos em contraposição à propriedade privada (vaga essa vinculada ao socialismo emergente no século XIX); outra ligada às viagens de “descobrimento", também situada a partir do século XVI, e que promoveu um amplo debate sobre as virtudes e vícios dos povos primitivos e autóctones do "novo" mundo; ainda outra, que emerge a partir do século XVII e que vincula descobertas científicas e inovações tecnológicas a um progresso indefinido da humanidade na direção de uma vida melhor, mais saudável e materialmente mais rica; por fim, uma vaga vinculada a uma busca por igualdade e liberdade que emerge a partir dos movimentos revolucionários francês e norte-americano no século XVIII (CLAEYS, SARGENT, 1999, p. 3-4). De forma análoga, a produção distópica também se vinculou a configurações histórico-políticas de emergência de instituições centralizadas de poder (totalitarismo) que ensejaram uma construção imaginária do mau lugar (CLAEYS, 2017).

A partir de uma reflexão filosófica sobre as utopias, Michel Foucault (2003) constrói a noção de heterotopia, que mantém uma tensão na busca por "espaços absolutamente outros" que, no entanto, não se reduzem à incorporalidade da utopia sem espaço e que pode ser incorporada às definições propostas por Clayes e Sargent (1999).

[...] sonho com uma ciência que teria por objeto esses espaços diferentes, esses outros lugares, essas contestações míticas e reais do espaço em que vivemos. Essa ciência estudaria não as utopias, pois é preciso reservar esse nome para o que verdadeiramente não tem lugar algum, mas as heterotopias, espaço absolutamente outros (FOUCAULT, 2003, p. 20-21). 
Essas heterotopias apontam para uma dinâmica de abertura e fechamento em relação ao espaço circundante, justapondo, em um espaço "real", possibilidades tópicas que a princípio seriam incompatíveis com a própria realidade em que são criadas (FOUCAULT 2003, p. 24-6). Essas características expõem uma dualidade do conceito de heterotopia, que, por um lado, configura espaços de contestação, de resistência e de luta, em contraposição à realidade em que está inserida, como quilombos; e que, por outro lado, reproduz ilusões em espaços configurados, "corrigindo" elementos da própria realidade hegemônica, como hospícios. Segundo o autor,

Elas são a contestação de todos os outros espaços, uma contestação que pode ser exercida de duas maneiras: ou como nas casas de tolerância de que Aragon falava, criando uma ilusão que denuncia todo o resto da realidade como ilusão ou, ao contrário, criando outro espaço real tão perfeito, tão meticuloso, tão bem disposto quanto o nosso é desordenado, mal posto e desarranjado (FOUCAULT, 2003, p. 28).

A partir de uma orientação conceitual que não está presente nas proposições teóricas mobilizadas anteriormente, a noção de anti-distopia aponta para uma esfera de atuação política, artística ou literária que, ao contrário da anti-utopia definida por Clayes (1999), figura como um movimento de contraposição a construções distópicas e seus desdobramentos performativos. Nesse sentido, o conceito de anti-distopia refere-se à negação de um estado atual de coisas, não através da busca por espaços outros no âmbito da própria realidade (heterotopia) ou representações de mundos possíveis (utopia), mas através de estratégias e negociações para forjar espaços de resistência e transformação em uma realidade que apresenta características distópicas. A concretude de tais espaços de resistência, ainda que fragmentados e não-planejados, caracterizaria a dimensão espaço-temporal de uma antidistopia.

Uma literatura anti-distópica trabalharia no sentido não só de reagir a um contexto ficcional ou sócio-histórico de caráter opressivo e autoritário, mas, igualmente, de agir sobre ele de modo a forjar espaços de liberdade que não poderiam ser utópicos, pois não atuam apontando para outros mundos virtuais, mas anti-distópicos, já que visam impactar criticamente este contexto em que está sendo produzida. A agência, a performatividade e a recepção da produção artística são elementos fundamentais da anti-distopia.

Por outro lado, a questão revolucionária (em sentido marxista, de tomada de poder por uma classe política dos trabalhadores/proletários) também não caracteriza corretamente esta literatura anti-distópica, pois um processo revolucionário para a tomada de poder não se 
configura como uma via privilegiada para promover as transformações a que se propõem enquanto possibilidade de resistência e crítica a uma dada realidade. A ausência de um projeto revolucionário que abranja a totalidade não deve, contudo, produzir uma caracterização como não-emancipatória, não-revolucionária ou mesmo escapista de produções anti-distópicas. Algumas posições apressadas e ortodoxas não lograriam, portanto, alcançar os motivos estabelecidos em tais obras, descrevendo-a de maneira alheia a ela própria.

A partir de uma simplificação dos conceitos aqui expostos, procurou-se estabelecer no Quadro 1 uma tipologia de categorias analíticas que possam ser utilizadas comparativamente.

Quadro 1 - Tipologia de configurações espaço-temporais

\begin{tabular}{|c|c|c|}
\hline Topos (lugar) & Ethos (caráter) & Características Gerais \\
\hline Utopia & Virtual-abstrata & $\begin{array}{c}\text { Espaços bons, idílicos, edênicos. } \\
\text { Detalhadamente planejados. Inexistente. } \\
\text { Parâmetro virtual. }\end{array}$ \\
\hline Distopia & Virtual-abstrata & $\begin{array}{c}\text { Espaços maus, repressivos, totalitários. } \\
\text { Detalhadamente controlados. Inexistente. } \\
\text { Parâmetro virtual. }\end{array}$ \\
\hline Heterotopia & Real-concreta & $\begin{array}{c}\text { Espaços ambíguos, simbolicamente não } \\
\text { hegemônicos. Mecanismos controlados de } \\
\text { entrada e saída. Possibilidade de existência } \\
\text { real. }\end{array}$ \\
\hline Anti-distopia & Real-concreta & $\begin{array}{c}\text { Espaços fragmentados, pouco ou nada } \\
\text { planejados. Resistência e crítica à realidade. } \\
\text { Possibilidade de existência real. }\end{array}$ \\
\hline
\end{tabular}

Fonte: Adaptada de Clayes (1999) e Foucault (2003). Elaboração própria.

O caráter (ethos) destas categorias espaço-temporais é definido tomando a realidade histórica como parâmetro. Por um lado, utopias e distopias são virtuais-abstratas; enquanto heterotopias e anti-distopias são reais-concretas. A diferença nesse caráter implica que é possível às duas últimas terem existência na realidade histórica, enquanto às duas primeiras é impossível, embora possam servir como parâmetro normativo para avaliação da realidade. Nesse sentido, utopias e distopias são como tipos ideais: não existem na realidade material, mas servem como parâmetro para avaliação de fenômenos empíricos. Essa discriminação é fundamental para sua mobilização metodológica.

Nessa abordagem, tomar a realidade histórica como parâmetro de definição doethos não implica na impossibilidade de sua existência ficcional. Ao contrário, a ficção é uma plataforma privilegiada para construção de utopias e distopias, como demonstra Clayes (1999, 
2017). Assim, é possível que existam realidades ficcionais em que haja contraposição ou justaposição destas mesmas categorias. Seria possível visualizar, por exemplo, a existência de um espectro contínuo desta tipologia: anti-distopias configuradas como espaços fragmentados no âmbito de uma realidade distópica, que ainda não se consolidaram como heterotopias e que se orientam por utopias para sua concretização.

A partir da tipologia e do referencial teórico apresentados nesta seção, será possível organizar uma leitura crítica profícua da obra de Torquato Neto. Em sua obra, contudo, a configuração das relações entre as categorias não é linear, mas dinâmica e oscilante, sendo possível perceber algumas regularidades que atravessam sua produção sem prejudicar a pluralidade dos universos poético-ficcionais erigidos pelo autor. As duas próximas seções do texto dedicam-se a analisar tais atravessamentos. Primeiramente, a partir da definição de um corpus delimitado que inclui a poesia e o cancioneiro do autor e, em um segundo momento, através de trechos de sua coluna Geléia Geral.

\section{PROJEÇÕES E SENSAÇÕES APOCALÍPTICAS NA POÉTICA DE TORQUATO NETO} (1968-1972)

Sobre a leitura crítica, orientou-se pelo objetivo de analisar sua conformação espaçotemporal em termos poéticos para, após uma análise preliminar, adaptar as categorias para a interpretação da obra ${ }^{5}$. Nesse sentido, as definições conceituais das categorias e da tipologia não foram feitas à parte ou anterior e posteriormente à leitura. Pelo contrário, as associações entre sua obra e as configurações espaço-temporais aqui definidas foram feitas a partir de sua própria produção literária e jornalística ${ }^{6}$, já que a identificação de uma realidade poética oscilante entre as categorias trabalhadas na tipologia (Quadro 1) foi possível, por exemplo, graças à percepção das menções repetidas ao vocábulo "fim" em diversos de seus poemas e canções, assim como a identificação de práticas discursivas anti-distópicas tornou-se possível a partir das leituras de Geléia Geral. Desse modo, além da proposição de uma análise crítica, este trabalho também assume a importância de uma interlocução direta com os textos (CANDIDO, 1985, 1993). Em suma, com a obra de Torquato Neto.

\footnotetext{
5 A adaptação das categorias analíticas e do esquema teórico envolve a flexibilização dos mesmos para operacionalizar uma análise literária. Assim, as categorias são entendidas para além da composição estética do espaço e tempo ficcionais, mas também para as relações entre eu-lírico, ambiente e as conformações sonoras, semânticas e imagéticas destas categorias.

${ }^{6}$ Esses procedimentos não indicam, contudo, que as categorias que compõem a tipologia possam ser usadas apenas para analisar a obra de Torquato Neto. Ao contrário, a partir do diálogo com Claeys (2017) e Foucault (2013) seria possível generalizar esses esquemas para analisar obras literárias, musicais, jornalísticas e epistolares de diferentes autores inseridos nas décadas de 1960-1970.
} 
A primeira característica identificada na obra como elemento de atravessamento é a já mencionada repetição ao vocábulo "fim", que contribuiu para conformar, por sua vez, o corpus da pesquisa. O Quadro 2 discrimina tais repetições e demonstra que a palavra foi mencionada 27 vezes nos poemas e canções elencadas. É importante pontuar que nem todas as produções que possuíam o vocábulo foram incluídas neste corpus, pois foram descartadas, a partir de leituras orientadas, aquelas que foram utilizadas com uma carga semântica distinta daquela que se está enfocando nesta análise, ou seja, o vocábulo "fim" articulado a categorias espaço-temporais na estrutura poética.

Quadro 2 - Corpus da pesquisa definido pela menção ao léxico "fim" (Poesia e Cancioneiro de Torquato Neto)

\begin{tabular}{|c|l|c|}
\hline \multirow{5}{*}{ Obra literária } & \multicolumn{1}{|c|}{ Título } & Léxico “fim” \\
\hline \multirow{5}{*}{ Poesia } & Literato Cantabile (2 ${ }^{\text {a versão) }}$ & 4 \\
\cline { 2 - 3 } & Literato Cantabile (1 ${ }^{\text {a }}$ versão) & 3 \\
\cline { 2 - 3 } & Cogito & 1 \\
\cline { 2 - 3 } & Mais desfrute, curta & 1 \\
\hline \multirow{5}{*}{ Cancioneiro } & Marginália II (1967) & 3 \\
\cline { 2 - 3 } & Mamãe, coragem (1968) & 3 \\
\cline { 2 - 3 } & Três da madrugada (1971) & 2 \\
\cline { 2 - 3 } & Dente no dente (1972) & 2 \\
\cline { 2 - 3 } & O nome do mistério (1970) & 1 \\
\cline { 2 - 3 } & Que película (1971) & 27 \\
\hline \multirow{2}{*}{ Total (menções) } & & \\
\hline
\end{tabular}

Fonte: NETO, 2004a. Elaboração própria.

Em última instância, o número de menções ao léxico é insuficiente para afirmar que se trata de um atravessamento fundamental da obra ficcional do autor. Desse modo, procedeu-se à análise crítica das produções com o objetivo de perceber se seu conteúdo e sua constituição formal possuíam regularidades que abranjam uma temática privilegiada da poética de Torquato Neto. Embora o espaço não permita organizar uma análise detalhada de todos os poemas e canções que compõem o corpus, serão destacados trechos que permitam encaminhar uma análise comparativa. 
Com maior número de menções ao vocábulo em sua poesia, Literato Cantabile, segundo Cravançola (2016), possui duas versões. Sua análise aponta para duas características fundamentais da poética de Torquato Neto no âmbito do período aqui delimitado (19681972): a fragmentação e a intratextualidade. É possível encontrar trechos e versos destes mesmos poemas na Geléia Geral e em seus Cadernos e Diários pessoais (NETO, 2004a), o que demonstra que, além de retalhos e reutilização, o autor também está em diálogo constante com a própria obra ao explorar reflexões a partir de textos semelhantes que, contudo, se distinguem e apresentam diferentes sentidos a partir de suas costuras. Para Calixto (2012, p. 62), a intratextualidade em Torquato conforma textos em que "a célula seguinte não é, de maneira alguma, idêntica à anterior. Pode completá-la o sentido, mas não é a mesma peça”.

Se as duas versões possuem um mesmo núcleo em torno do perigo e da desconfiança em relação às palavras ${ }^{7}$, tidas como precipício (verso $20,1^{\mathrm{a}}$ versão) e cilada (verso $2,2^{\mathrm{a}}$ versão), as caracterizações espaciais das duas versões se modificam substancialmente. Ainda que em ambas as figurações distópicas sejam explícitas, a $1^{\text {a }}$ versão enfatiza um ambiente de guerra que levaria os literatos para o hospício, dando ênfase em uma dimensão de conflito; trata-se de uma caracterização espaço-temporal de um ambiente pós-guerra ("a guerra acabou") e de isolamento de grupo específico de pessoas ("e os literatos foram todos para o hospício"). A $2^{\mathrm{a}}$ versão, por sua vez, identifica um ambiente estático e completamente controlado: uma realidade totalitária em que a própria subjetividade (gestos e movimentos) é solapada pela opressão do espaço ("E qualquer gesto é o fim/Do seu início”).

Em ambos os poemas percebe-se uma caracterização distópica, mas suas configurações espaço-temporais se distinguem, por exemplo, pelo que podem ser descritos como espaços heterotópicos: se na $1^{\mathrm{a}}$ versão o hospício opera como um espaço de fuga em que se perde a noção de tempo ("não se sabe nunca mais do fim"), na $2^{\mathrm{a}}$ o hospício é associado à própria realidade distópica e totalitária, habitada pela transparência do silêncio (da fala) e pelo canto dos pássaros (“Os pássaros de sempre cantam nos hospícios”). Neste, a fuga, como espaço de liberdade e não necessariamente de isolamento, materializa-se na república ("nome da república") em contraposição ao hospício.

A lógica das relações entre as categorias de espaço e de tempo, de distopia e de heteropia, embora esteja presente nas duas versões, modifica-se em relação aos significados dos espaços heterotópicos face à própria realidade, o que direciona para a característica de

\footnotetext{
${ }^{7}$ Não é fortuito relembrar essa característica comum a algumas obras distópicas clássicas: a utilização da língua e da linguagem como instrumento de dominação, como a novilíngua (newspeak) em 1984, de George Orwell, e a ambígua relação com a literatura em Admirável Mundo Novo, de Aldous Huxley.
} 
ambiguidade das heterotopias,como conceituada por Foucault (2003). Na 1a , o hospício como fuga para literatos em chave de isolamento; na $2^{\mathrm{a}}$, a república como espaço de liberdade em contraposição ao hospício, aqui espaço de controle e dominação. Ainda que seja possível sugerir que os poemas tenham um mesmo eu-lírico, a construção das realidades poéticas é distinta. A oscilação, nesse sentido, ocorre a partir de uma mesma caracterização distópica do espaço-tempo.

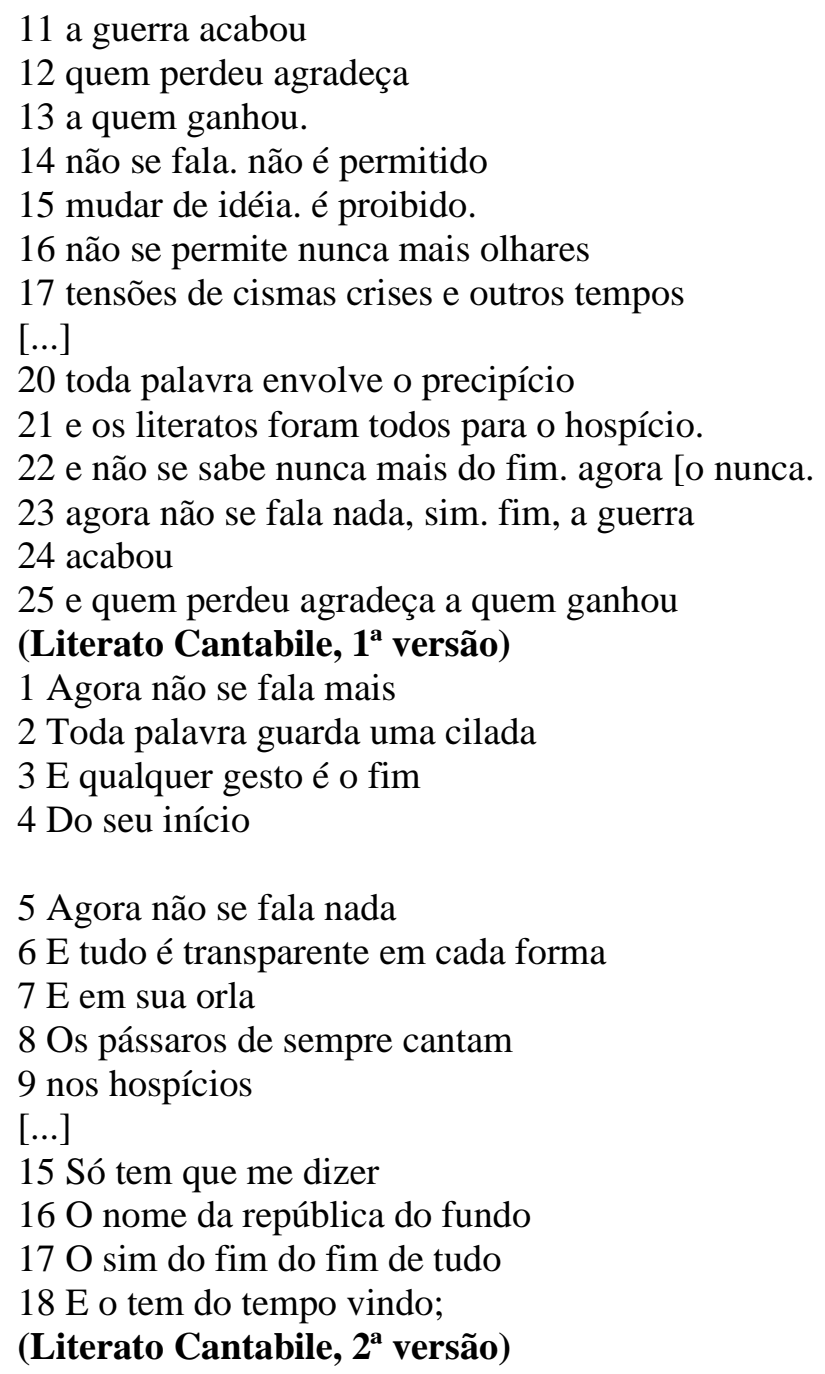

Em outra chave de leitura, o poema Cogito, que consta entre os mais conhecidos da poesia torquateana, apresenta uma relação distinta entre ambiente e eu-lírico: ainda que haja uma ambientação apocalíptica ("todas as horas do fim"), o eu-lírico, evocando o cogito cartesiano ("eu sou como eu sou"), subverte-o para além de uma personalidade isolada em meditação ("medida do impossível", "vidente", "tranquilamente”). Desse modo, a homologia entre início/impossível e fim/tranquilamente demonstra um espaço de agência do sujeito em relação a seu tempo, elemento importante para caracterização de uma prática anti-distópica. 
Ainda que o poema não traga explicitamente um recurso à ação, traz uma postura de ensaio entre a resistência e a indiferença. Sujeito anti-distópico em uma realidade distópica (apocalíptica), demonstrando a inflexão nessas categorias.

Se em Literato Cantabile há uma realidade distópica em que o eu-lírico projeta espaços heterotópicos como possibilidade de fuga, em Cogito, do mesmo modo, tem-se a presença de uma distopia em que o eu-lírico, por outro lado, se posiciona "tranquilamente" como pessoa intransferível, "na medida do impossível" da própria realidade em que (sobre)vive.

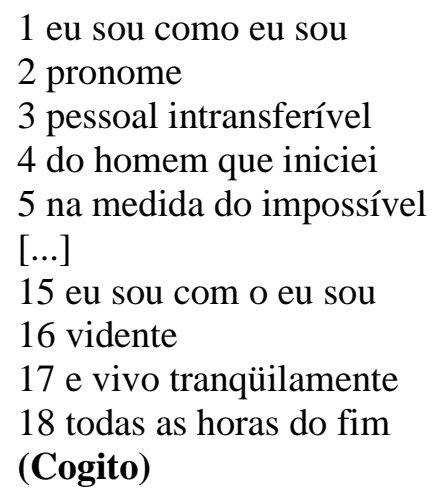

Por outro lado, em Mais desfrute, curta a realidade se encontra entre a virtude e o vício, ambos no início e no fim da chave. A partir de símbolos sugestivos, este poema articula imagens esteticamente complexas e incômodas, particularmente na quarta estrofe: urubus no telhado, carne seca servida, escorpião encravado na própria ferida. A famosa crença de que escorpiões, quando encurralados, lançam o ferrão sobre o próprio corpo reaparece em uma cena onde urubus parecem esperar o suicídio do aracnídeo.

Se, por um lado, a linguagem e a configuração de versos do poema são fluídas e velozes, as imagens e o tom de desespero conformam uma realidade fatal: se Deus é precipício, nem o hospício é refúgio (heterotopia). Não há espaço de fuga. Apenas a porta da saída como escape fatal. Trata-se, de fato, de uma distopia fatalista tanto na caracterização do ambiente quanto nas posições do eu-lírico frente a ele.

5 b) A virtude e o próprio vício

6 - conforme se sabe -

7 estão no fim, no início

8 da escada. Chave.

[...]

15 d) (amar-te/a morte/morrer:

16 há urubus no telhado e a carne seca

17 é servida: um escorpião encravado 
18 na sua própria ferida, não escapo: só escapo

19 pela porta da saída).

[...]

29 f) A virtude

30 mais o vício: início da

31 MINHA

32 transa, início, fácil, termino:

33 "como dois mais dois são cinco"

34 como Deus é precipício,

35 durma,

36 e nem com Deus no hospício

37 (durma) nem o hospício

38 é refúgio. Fuja.

(Mais desfrute, curta)

Se em sua obra poética há uma predominância de realidades fortemente distópicas, mas oscilação no comportamento do eu-lírico entre fuga heterotópica, postura anti-distópica e fatalismo distópico, o cancioneiro de Torquato Neto, por sua vez, apresenta uma diversidade maior de configurações espaço-temporais, ultrapassando, ainda que timidamente, a caracterização distópica e pessimista de parte considerável de sua poesia pós-tropicalista aqui analisada ${ }^{8}$.

A letra de Marginália II, sendo o texto do corpus com maior menção ao vocábulo “fim” em função de seu refrão, já citada no início deste texto, apresenta tons de uma estética fortemente tropicalista. Ainda que haja uma dimensão apocalíptica presente em seu refrão (“Aqui é o fim do mundo") e entre os versos 21 e 23 (“Conheço bem minha história/[...]/E termina antes do fim"), não seria correto afirmar que a canção seja caracterizada por uma dimensão exclusivamente distópica, já que suas outras estrofes caracterizam, mais do que uma narrativa poética, uma reflexão sobre o território e a identidade nacionais.

Nesse sentido, se a quarta estrofe representa uma dimensão idílica, romântica e, portanto, utópica da nacionalidade ("Entre cascatas, palmeiras/Araçás e bananeiras/Ao canto da juriti”), a oitava estrofe representa uma dimensão pessimista, melancólica e, portanto, distópica dessa mesma nacionalidade ("Onde sopra o vento forte/Da fome, do medo e muito/Principalmente da morte"), mas não a toma como inevitável e fatal e sim derivada de condições políticas (“Aqui, o Terceiro Mundo”), ressaltando uma dimensão contraditória da própria nacionalidade que, nos termos propostos nesta análise, oscilam entre uma fabulação utópica, uma denúncia anti-distópica e uma produção social e política da realidade distópica,

\footnotetext{
${ }^{8}$ É importante ressaltar que há outros atravessamentos de leituras possíveis que esta pesquisa não contemplou. Cravançola (2016), por exemplo, analisa a presença da melancolia na obra de Torquato Neto.
} 
conduzindo a uma operação de contradições estéticas ("pânico e glória/laço e cadeia") reconhecidamente tropicalistas (XAVIER, 1993).

19 Aqui, meu pânico e glória

20 Aqui, meu laço e cadeia

21 Conheço bem minha história

22 Começa na lua cheia

23 E termina antes do fim

24 Aqui é o fim do mundo

(Marginália II, 1968)

Em Mamãe, Coragem, canção presente no consagrado disco-manifesto Tropicália ou Panis et Circencis (1968), há um tom de consolação. Um filho que consola a mãe por a ter deixado para residir em outro local, mas que está bem (“Eu por aqui, vou indo muito bem”). Um eu-lírico com possibilidades diversas de vontade e ação ("Eu quero, eu posso, eu quis, eu fiz"), alguém que planta uma cidade (“cidade que plantei pra mim"). Uma cidade sem fim, onde se brinca de carnaval e se vive felicidade. Uma cidade de forte caracterização utópica. Ainda que haja um leve tom melancólico em relação à despedida do filho, sua postura é de consolo e conselho à mãe, narrando a ela sua experiência em uma cidade utópica "que não tem mais fim". Encontra-se aqui o primeiro texto em que o vocábulo "fim" aparece em chave positiva, diferentemente da $1^{\mathrm{a}}$ versão de Literato Cantabile, em que a negação do fim está em chave de fuga, de negação da realidade.

\footnotetext{
24 Eu por aqui, vou indo muito bem

25 De vez em quando brinco carnaval

$26 \mathrm{E}$ vou vivendo assim

27 Felicidade na cidade que eu plantei pra mim

28 E que não tem mais fim, não tem mais fim

29 Não tem mais fim
}

(Mamãe, coragem, 1968)

Se em Mamãe, coragem a cidade é que não tem fim, em Três da madrugada o que não tem fim é a rua de uma cidade abandonada ("A cidade abandonada/E essa rua que não tem mais fim"). O eu-lírico afirma que possui um coração pobre, que não vale nada: uma rua sem sons, sem palavras e sem fim. Há, por um lado, forte caracterização heterotópica da rua por influência da subjetividade melancólica do próprio eu-lírico, considerando que "a heterotopia tem como regra justapor em um lugar real vários espaços que, normalmente, seriam ou deveriam ser incompatíveis" (FOUCAULT, 2013, p. 26); por outro, há um forte tom 
apocalíptico de abandono e solidão "sem fim”. Aqui, a própria caracterização espaçotemporal está articulada em função da subjetividade do eu-lírico. Pode-se dizer que o próprio sujeito encontra-se em uma situação psicológica entre a distopia e a heterotopia.

\author{
1 Três da madrugada \\ 2 Quase nada \\ 3 A cidade abandonada \\ 4 E essa rua que não tem \\ mais fim \\ $[\ldots]$ \\ 19 Meu pobre coração não vale nada \\ 20 Pelas três da madrugada \\ 21 Toda a palavra calada \\ 22 Dessa rua da cidade \\ 23 Que não tem mais fim \\ (Três da madrugada, 1971)
}

Em Dente no dente há, novamente, uma operação intratextual com Literato Cantabile na expressão "o fim do fim de tudo" que, naquele poema, aponta para um futuro possível em contraposição ao "início do fim", expressão que marcaria uma situação presente de controle totalitário. Na canção, por sua vez, é possível perceber uma ação combativa do eu-lírico em relação ao presente ao fazer referência à expressão "olho por olho, dente por dente". Diferentemente de Literato Cantabile, o eu-lírico aqui, ainda que pareça negar a realidade presente, vislumbra um futuro, vislumbra o fim do fim de tudo, que não é o hospício nem a república e não é na madrugada. Não é fuga. É no começo da chave: no sol poente. Uma imagem explicitamente utópica. Projeta-se o fim do fim (o futuro) ao fim da tarde. A timidez de uma postura anti-distópica em relação ao presente é diluída na projeção de um futuro utópico.

\footnotetext{
8 Olho no olho, dente no dente

9 Lentamente, é nesse hora a hora

10 Que eu desejo o fim do fim de tudo

11 É no começo, e o sol poente

(Dente no dente, 1972)
}

Em $O$ nome do mistério repetem-se expressões já comuns aos textos anteriores: “fim de tudo", presente nas duas versões de Literato Cantabile e em Dente no dente, bem como "fim do mundo", presente em Marginália II. A mera repetição desses vocábulos e expressões não implica, necessariamente, uma intratextualidade, como ocorre em outros textos, mas indica a importância desse léxico para a produção poética de Torquato Neto. Naquela canção, 
esse léxico é flexionado a partir de uma situação em que o eu-lírico parece sofrer por amor, carregando a sensação de um tom melancólico e pessimista ("agora é tarde", "nosso amor é outro", "só nos resta alguns papéis/para rasgar", "nosso amor é morto").

Os versos 4 e 5, 10 e 11 é que se tornam ambíguos na medida em que podem se referir tanto ao tempo amoroso quanto ao tempo presente ("Que o nosso tempo agora/É o fim de tudo/[...]/é o fim do mundo"). Nesse sentido, ainda que a dimensão temporal aqui se refira especificamente ao amor, a utilização dessas expressões remete, novamente, a uma perspectiva apocalíptica, embora sua carga semântica nessa canção não esteja diretamente articulada às dimensões espaço-temporais, mas indiretamente, já que expõe um conteúdo ambíguo ou, em uma interpretação livre, um amor apocalíptico.

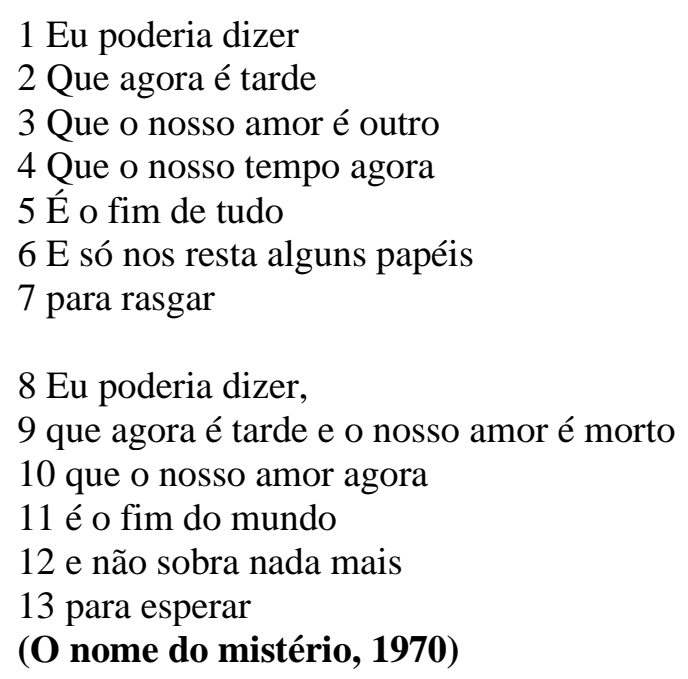

Na bela letra de Que película, canção pouca conhecida na obra de Torquato Neto, o conteúdo parece indicar uma despedida do eu-lírico de alguém querido, alguém recentemente falecido ("De nunca mais sem mais adeus pra mim"). Alguém que chegou ao fim. O tom, mesmo com carga melancólica, aponta para belas imagens de esperança, especialmente a plasticidade e as rimas dos versos 17 e 19 ("Plastificando e desfolhando azuis/[...]Eu vi você iluminando a luz”). A despedida e a morte dão lugar à esperança plástica no azul celeste e, como em Dente no dente, no sol poente.

17 Plastificando e desfolhando azuis

18 De nunca mais sem mais adeus pra mim

19 Eu vi você iluminando a luz

$20 \mathrm{Eu}$ vi você chegando ao fim

(Que película, 1971) 
Embora essas análises não consigam dar conta da complexidade dos textos aqui elencados e pareça, à primeira vista, simplificações encaixadas, seu objetivo é explorar a possibilidade de uma leitura crítica comparativa da obra do autor. Essa leitura torna possível afirmar que há na obra poética de Torquato Neto, em primeiro lugar, construções espaçotemporais articuladas ao vocábulo "fim”. Essas construções são oscilantes e foram pensadas a partir da tipologia articulada neste texto. Ainda que a tipologia não seja representativa da obra poética em sua totalidade, constituindo, necessariamente, uma redução de determinados elementos formais e maior foco analítico em outros, como espaço e tempo, as categorias tornaram possível perceber, em segundo lugar, a existência predominante de projeções e sensações apocalípticas em sua obra poética, constante em sua poesia e oscilante em seu cancioneiro.

Assim é que as versões de Literato Cantabile, Cogito, Mais desfrute, curta, Marginália II e Três da madrugada possuem projeções e sensações apocalípticas que, embora diversificadas em suas construções, são identificadas tanto em seu léxico como em sua configuração espaço-temporal. Essas projeções oscilam consideravelmente em Mamãe, coragem, Dente no dente e Que película, com tons e imagens utópicas, seja na própria realidade presente ou em uma possibilidade de futuro.

Em outra chave de leitura, apesar da hegemonia de projeções e sensações apocalípticas, é possível identificar maior oscilação em relação ao modo como o eu-lírico se posiciona em sua realidade: em Literato Cantabile projeta-se espaços heterotópicos, sujeitos em fuga; em Cogito e Dente no dente, através de uma indiferença blasé e de um escapismo reativo, sujeitos em resistência; em Mamãe, coragem e Que película, corpos utópicos, para utilizar uma expressão de Foucault (2003); em Marginália II, apocalipse político; e, por fim, em Mais desfrute, curta e Três da madrugada, sujeitos pessimistas, apocalípticos. Corpos distópicos.

Entre sensações distópicas e utópicas, Torquato Neto encontra alternativas (ou não) na fuga, na indiferença e na resistência. Afinal, para o autor, “o apocalipse, aqui, será apenas uma espécie de caos no interior tenebroso da semântica. Salve-se quem puder” (NETO, 2004a, p. 311). Todos anseiam a salvação, alguns lutam por pedaços dela. Aqui é que se chega na Geléia Geral. 


\section{A GELÉIA GERAL (1971-1972) COMO ESPAÇO ANTI-DISTÓPICO}

A passagem analítica de obras literárias para colunas jornalísticas ou correspondências pessoais não deve ser feita de maneira automática, mas a partir de critérios e pressupostos metodológicos consistentes. Se for possível afirmar que obras literárias constituem universos ficcionais relativamente autônomos da realidade histórica, o mesmo não poderia ser assumido de maneira inconsequente em relação a matérias jornalísticas ou correspondências pessoais, ainda que seja importante reconhecer suas semelhanças e as implicações que disso derivam. Não caberia organizar uma extensa discussão sobre o assunto e suas polêmicas, amplamente trabalhada por historiadores, sociólogos e críticos literários (CAMILOTTI, NAXARA, 2009; GRECCO, 2014; HANSEN, 2019). É preciso estabelecer, contudo, que neste trabalho tomase obras literárias como estruturas estéticas relativamente autônomas da realidade histórica e colunas jornalísticas como documentos históricos que possuem compromissos intrínsecos com a realidade social em que são produzidas. Esses pressupostos, contudo, não anulam o reconhecimento da historicidade de obras literárias e tampouco nega a presença de elementos estéticos na atividade jornalística.

Essa rígida demarcação teórico-metodológica, inclusive, passaria ao largo da própria produção literária e jornalística de Torquato Neto, especialmente se se considerar que, a partir de suas produções tropicalistas, o conceito de obra é deslocado para a própria existência do artista, implicando em uma difícil demarcação entre vida e obra, estética e existência $\left(\right.$ HOLLANDA, 2004) ${ }^{9}$. Do mesmo modo, suas colunas jornalísticas, especialmente Geléia Geral, se utilizam de experimentações em tom artístico e coloquial, lançando mão de colagens poéticas, reprodução de versos diversos, gírias engraçadas e formatações incomuns em relação à tradição jornalística da grande imprensa. Não é sem motivo que Pires $(2004$, p. 18), ao falar de Geléia Geral, usa um tom eufórico:

No contexto da grande imprensa, engessada de diversas formas pela censura, Geléia Geral é, mais do que um oásis de liberdade, uma aberração. Enclave da imprensa alternativa num jornal de grande circulação, fonte de informação preciosa, posto avançado da boa e agressiva polêmica, conclamação a uma mobilização política que, bem ao gosto da época, não está nos partidos ou nos movimentos, mas na própria existência.

\footnotetext{
${ }^{9}$ Este é um ponto delicado para estudiosos da obra de Torquato Neto. Ao assumir uma completa fluidez entre vida e obra, não é raro recair na construção de um personagem fictício ou de um mito, nas palavras de Pires (2001), ora ignorando sua trajetória como sujeito histórico, ora historicizando sua obra em chave determinista. É preciso lembrar, contudo, que a dissolução entre vida e obra como princípio estético não é generalizada na produção de Torquato Neto, mas passa a ser elaborada a partir de sua virada tropicalista e radicalizada em sua passagem "pós-tropicalista", da qual tratamos aqui de maneira privilegiada.
} 
Em um registro de 14 de setembro de 1971, na Geléia Geral, o próprio autor assume essa característica como compromisso (est)ético de sua produção:

Escute, meu chapa: um poeta não se faz com versos. É o risco, é estar sempre a perigo sem medo, é inventar o perigo e estar sempre recriando dificuldades pelo menos maiores, é destruir a linguagem e explodir com ela. Nada no bolso e nas mãos. Sabendo: perigoso, divino, maravilhoso (NETO, 2004b, p. 227).

A coluna, portanto, não deve ser lida apenas como documento histórico, mas como uma síntese entre o histórico e o ficcional que pode ser tomada como registro histórico, cabendo atenção em não desconsiderar seu caráter estético e artístico.

Tais características, ainda que sejam fundamentais por marcarem a hibridez da produção jornalística de Torquato Neto, não autorizam de antemão a utilização do referencial teórico construído neste texto para estudar sua produção não-poética. Em consequência disso, foi necessário realizar uma adaptação conceitual, não sem alguma licença poética, mas assumida desde então. Desse modo, se a anti-distopia é pensada como espaços fragmentados e pouco planejados de resistência e contestação a uma realidade distópica, pode-se dotá-lo de historicidade e inseri-lo em uma dada realidade social. Ainda que, a priori, a obra nãoficcional não se refira, não esteja inserida ou não faça projeção de uma realidade distópica e, por extensão, a espaços anti-distópicos ${ }^{10}$, se se manter a terminologia, feita as devidas adaptações, a anti-distopia poderia ser estendida e adequar-se à noção de práticas discursivas (de caracteres múltiplos) que podem ou não forjar espaços de resistência em uma realidade autoritária, como foi a ditadura militar brasileira.

Feita essa manobra teórico-metodológica, a discussão recai sobre um tema clássico na produção crítica, historiográfica e sociológica: o caráter político e crítico das produções culturais e artísticas nas décadas de 1960-1970 (HOOPER, 2017). Dentre a diversidade da produção bibliográfica de época, destaca-se aqui o trabalho de Luciano Martins (2004), escrito em 1979. Embora não seja objetivo deste trabalho avançar em uma discussão bibliográfica de sua obra, algo organizado por Hooper (2017), é importante demarcar suas posições para que se possa compreender em que medida o argumento aqui defendido se aproxima ou se distancia de suas argumentações.

\footnotetext{
${ }^{10}$ Como foi argumentado a partir de Clayes (2017), tais configurações espaço-temporais não possuem realidade empírica, mas se referem a representações imaginárias ficcionais, literárias ou não.
} 
Martins (2004) classificou um grupo social de jovens de classe média urbana do fim da década de 1960 pela denominação de "geração AI-5", que se caracterizaria, em linhas gerais, por três pilares: pela adesão aos valores da chamada contracultura, pelo escapismo da realidade através do uso de drogas e pelo modismo da psicanálise, características originadas pela frustração de um projeto de reação, restando-lhes a alienação à repressão imposta pelo regime militar e, especialmente, por sua radicalização a partir do AI-5. Segundo suas palavras:

\begin{abstract}
A ideologia explicitamente autoritária é substituída, assim, por um difusa "cultura autoritária", que se transmite à sociedade pelas práticas cotidianas da censura, da violência policial, da arrogância da burocracia, do desrespeito aos direitos individuais, da ocultação do processo decisório. Práticas essas que começam a condicionar a existência dos indivíduos na medida em que, não apenas passam a definir as relações entre poder e sociedade, mas penetram e ordenam os mais variados domínios da vida cotidiana. Em tais condições, e como reação defensiva a essa "cultura autoritária", começa a emergir uma contracultura, também difusa, através da qual grupos sociais mais ou menos restritos procuram preservar, sob a forma de pautas individuais de comportamento, aquilo que percebem, com maior ou menor clareza, lhes estar sendo negado: a condição de sujeito de suas existências. [...] É pela reafirmação, que pode ser ingênua ou não, desse valor negado que a contracultura se organiza (MARTINS, 2004, p. 16).
\end{abstract}

Em oposição a essa perspectiva, este trabalho aprofunda as perspectivas de Renato Ortiz (2001) e Gilberto Velho (1977) de que houve articulações entre aquele grupo de jovens e artistas que visou não apenas reagir ao autoritarismo, como também forjar estratégias de resistência política a partir de negociações com instituições estatais e criação de espaços sociais de oposição. Na obra jornalística e nas correspondências de Torquato Neto, jovem artista que poderia ser inserido na chamada "geração AI-5", esta problemática aparece de maneira privilegiada, demonstrando posições controversas que ilustram a reflexividade de um ator social, inclusive em relação à sua própria "geração", inserido em um contexto autoritário.

Se, por um lado, as produções de Torquato Neto podem ser compreendidas como ações de resistência política à ditadura militar, por outro, seus ácidos posicionamentos também denunciam uma postura próxima àquela discutida por Martins (2004), aqui descrita privilegiadamente por um ator social inserido nos acontecimentos históricos. Em uma carta a Hélio Oiticica datada de 16 de julho de 1971, artista plástico de quem o poeta se torna íntimo a partir de 1968, Torquato Neto reclama de posturas "escapistas" e "alienantes" de pessoas da “espécie de [José Carlos] Capinam”, com quem compartilhou composições e interações à época do álbum Tropicália ou Panis et Circensis (1968). Em suas palavras: 
Hélio, aqui, é que ninguém mais tem opinião sobre coisa alguma. Todo mundo virou uma espécie de Capinam (esse é o único de quem eu não gosto mesmo: é muito burro e mesquinho), e o que eu chamo de conformismo geral, é isso mesmo, a burrice, a queimação de fumo o dia inteiro, como se isso fosse curtição, aqui é escapismo, vanguardismo de Capinam que é o geral, enfim, poesia sem poesia, papo furado, ninguém está em jogo, uma droga. Tudo parado, odeio (NETO, 2004a, p. 233).

Esse posicionamento, contudo, não se restringe à "esfera privada" das correspondências, mas é veiculado, embora sem menção a nomes, em sua coluna jornalística, que manteve no mesmo período, Em 19 de agosto de 1971, na primeira coluna de Geléia Geral, intitulada cordiais saudações (em minúscula) o autor critica o "conformismo dos inocentes" disfarçado de "lamúrias, ataques apocalípticos e desespero sem fim".

E que, enquanto você curte lá o seu tempo de espera, enquanto você espera um dilúvio que apague o fogo, seu ídolo, nosso ídolo, vem reafirmar tranqüilamente, para o Brasil inteiro, que estar vivo significa estar tentando sempre, estar caminhando entre as dificuldades, estar fazendo as coisas, e sem a menor inocência. Os inocen-tes estão esperando enquanto aproveitam para curtir bastante conformismo disfarçado em lamúrias, ataques apocalípticos e desespero sem fim (NETO, 2004b, p. 200).

Suas práticas, tentando ultrapassar o "conformismo" e as "derrotas" impostas pelo controle e censura da ditadura, possuem um caráter anti-distópico na medida em que se empenham em ocupar, forjar ou criar espaços de resistência e contestação a uma dada realidade. Em termos históricos, há um esforço individual e coletivo em garantir alguma presença, através da ocupação e criação de espaços críticos, em instituições marcadas pela repressão e censura do regime político autoritário. Em uma carta endereçada a Almir Muniz, escrita entre 1971 e 1972, Torquato Neto expõe o esforço em ocupar e criar espaços de crítica e contestação, sem "transar derrotas":

escute: não está na hora de transar derrotas, eu digo na porra da geléia: ocupar espaço, amigo, estou sabendo, como você, que não está podendo haver jornalismo no brasil e que - já que não deixam — o jeito é tentar, não tem outro que não seja desistir, e eu sinceramente acredito que não está na hora de desistir: ou a gente ocupa e mantém a porra do espaço, pra utilizá-lo, pra transar, ou a gente desiste, eu prefiro o "sacrifício". [...] pintemos onde? onde pudermos, pintemos nos jornais, por exemplo: só se publica o que é possível, mas se redige com o quer. não vamos desistir: entregar é agora ali dentro e naquele papo, transar derrotas satisfeitas, isso não é possível, aqui, agora (NETO, 2004a, p. 286-288). 
Assim como suas críticas ao conformismo e ao escapismo à sua "geração", suas estratégias e práticas anti-distópicas são expostas em colunas da Geléia Geral. Em uma coluna de 2 de novembro de 1971, intitulada "mais conversa fiada", o autor expõe seu apelo à ocupação e conquista de espaços anti-distópicos, como sua própria coluna, mas não se restringe a isso. Assim como faz um apelo à resistência, coloca a si mesmo uma negação da heterotopia como refúgio: "Abaixo os meus refúgios, chega", para declarar, definitivamente, "disponham: em primeiro lugar, o espaço". Sua recusa à heterotopia e o desafio de uma realidade apocalíptica constituem sua alternativa à anti-distopia como recurso e ferramenta contra a censura.

1 - E agora? Eu não conheço uma resposta melhor do que esta: vamos continuar. E a primeira providência continua sendo a mesma de sempre: conquistar espaço, ocupar espaço. Inventar os filmes, fornecer argumentos para os senhores historiadores que ainda vão pintar, mais tarde, depois que a vida não se extinga. Aqui como em toda parte: agora. [...] E agora? Continuemos, parar é que não é possível. Apocalipse só se for agora, eu só quero saber do que pode dar certo e não é perto nem está no fim. Faz um ano que eu me dizia, no hospício: isso aqui não pode ser um refúgio e foi assim que eu saí por aí, foi por isso. Abaixo os meus refúgios, chega. [...] $10-$ Disponham: em primeiro lugar, o espaço. 11 - E o fim no começo, como sempre. (NETO, 2004b, p. 286).

Esse apelo à ocupação de espaços, contudo, não é solto no ar. Em uma coluna de 30 de novembro de 1971, intitulada "filmes", o próprio autor fornece uma definição para sua proposição. Em suas considerações, não se trata literalmente de algo restrito à esfera "subterrânea", underground, contracultural, mas, de fato, como uma possibilidade de resistência e crítica à realidade ditatorial. Pela "superfície, de noite e com muito veneno". Em circunstâncias múltiplas, o autor utiliza as imagens de "brechas" e "rachas" para caracterizar tais espaços, o que indica o caráter fragmentário de anti-distopias como configuração espaçotemporal possível, em que "a cara também se quebra".

Ocupar espaço, num limite de "tradução", quer dizer tomar o lugar. Não tem nada a ver com subterrânea (num sentido literal), e está mesmo pela superfície, de noite e com muito veneno. Com sol e com chuva. Dentro de casa, na rua [...] Sem começo e sem fim, mas mesmo assim: pelas brechas, pelas rachas. Buraco também se cava e a cara também se quebra (NETO, 2004b, p. 315-316).

Estas considerações permitem classificar a Geléia Geral como um espaço antidistópico, que tentou forjar e criar espaços de resistência à censura e críticas ao regime militar 
em um jornal de grande circulação à época, Última Hora. Ainda que esta pesquisa não consiga mensurar os possíveis impactos da coluna na realidade política e social do país, sua própria existência em um jornal de grande circulação configura-se como um drible na censura. Uma brecha, uma racha, não apenas em consumo "underground", mas "pela superfície, de noite e com muito veneno. Com sol e com chuva. Dentro de casa, na rua”.

\section{CONSIDERAÇÕES FINAIS}

Em Torquato Neto, as caracterizações espaço-temporais são múltiplas. Em diversos momentos de sua obra poética, a construção formal do ambiente é associada ao vocábulo “fim”, nem sempre em tom distópico, embora haja predominância de projeções e sensações apocalípticas. Há uma oscilação de ambientes: utópicos, distópicos e heterotópicos; essa ambientação é perpetuada ou contestada pelas polêmicas posições de 'eu-líricos' torquateanos. Em sua coluna Geléia Geral, por outro lado, há uma recusa do escapismo utópico e da fuga heterotópica, esforçando-se por constituir práticas discursivas e produções culturais anti-distópicas, caracterizadas pelo esforço em forjar espaços de resistência e transformação à ditadura militar.

Assim como indica a análise da obra do poeta, parece mais profícuo compreender a diversidade de práticas, posturas, ações e reações a um contexto autoritário ou distópico a partir de suas oscilações, inclusive dentro de um mesmo grupo social ou produção cultural. Desse modo, considerando a mediação do contexto histórico sinteticamente caracterizado ao longo das seções do texto, sustenta-se a hipótese de que as produções artísticas e as ações políticas de determinados grupos sociais nas décadas de 1960 e 1970 não podem ser entendidas de maneira homogênea, precipitando-se como exclusivamente utópicas (escapistas) ou distópicas (fatalistas), mas oscilariam entre uma postura escapista, projetando realidades inacessíveis, e ações políticas, artísticas ou culturais de resistência e crítica, assumindo negociações, radicalizações e concessões, em que se acentua ou diminui a criticidade com o objetivo de impactar uma dada realidade social ou contexto de violência e autoritarismo.

Não se trata, portanto, de uma total negação das posições sociológicas clássicas sobre as produções culturais das décadas de 1960-1970. O trabalho de Luciano Martins (2004), por exemplo, identifica a existência de uma "cultura autoritária" que afeta negativamente a subjetividade dos sujeitos inseridos nesse contexto, algo fundamental para sua compreensão. Ainda que importante em termos teóricos e políticos, trata-se, segundo expressão de Ortiz 
(2001), de deslocar a ênfase em um 'sujeito alienado' à consideração de sua agência e reflexividade como sujeito histórico, que não apenas busca possibilidades de reações frustradas à opressão, mas formula e se apropria de estratégias de resistência.

Em pesquisas futuras, é possível explorar outras possibilidades teóricas e empíricas do conceito de anti-distopia, concentrando-se em sua existência reflexiva como práticas, discursos e estratégias, procedendo a uma síntese teórica que perpassaria os trabalhos de Michel Foucault (2000), Michel de Certeau (1998), Luc Boltanski (2011), Patrick Baert e Marcus Morgan (2018), adequando e adaptando seus corpos teóricos à realidade histórica, observando também suas potencialidades políticas para sobreviver a esta realidade histórica de características distópicas e apocalípticas. Por enquanto, é pertinente seguir Torquato (2004b, p. 320): "Meio e fim. O fim no começo, como sempre, e o meio mesmo eu não revelo. Onde fica?".

\section{REFERÊNCIAS}

BAERT, Patrick; MORGAN, Marcus. A performative framework for the study of intellectuals. European Journal of Social Theory, v. 21, n. 3, p. 322-339, 2018.

BOLTANSKI, Luc. On critique: a sociology of emancipation. Cambridge/Malden: Polity Press, 2011.

CALIXTO, Fabiano Antonio. Um poeta não se faz com versos: tensões poéticas na obra de Torquato Neto. 2012. Dissertação (Mestrado em Teoria Literária e Literatura Comparada) Faculdade de Filosofia, Letras e Ciências Humanas, Universidade de São Paulo, São Paulo, 2012.

CAMILOTTI, Virgínia; NAXARA, Márcia Regina C. História e Literatura: fontes literárias na produção historiográfica recente no Brasil. História: Questões \& Debates, Editora UFPR: Curitiba, n. 50, p. 15-49, 2009. Disponível em: https://revistas.ufpr.br/historia/article/view/15670. Acesso em: 08 de out. de 2019.

CANDIDO, Antonio. Prefácio. In: Na sala de aula: caderno de análise literária. São Paulo: Ática, 1985. p. 5-6.

CANDIDO, Antonio. Préfacio. In: O discurso e a cidade. São Paulo: Duas Cidades, 1993. p. 9-15.

CERTEAU, Michel de. A invenção do cotidiano: artes de fazer. Rio de Janeiro: Vozes, 1998.

CLAEYS, Gregory. Dystopia: A Natural History. Oxford: Oxford University Press, 2017. 
CLAEYS, Gregory; SARGENT, Lyman T. The Utopia Reader. New York: New York University Press, 1999.

CRAVANÇOLA, Esmeralda Barbosa. A poética de Torquato Neto: uma viagem perdida na noite escura dos anos 1960. In: XV ENCONTRO ABRALIC, 2016, Rio de Janeiro. Experiências literárias, textualidades contemporâneas. Rio de Janeiro: Dialogarts Publicações, 2016. v. $1 . \quad$ p. 5595-5604. Disponível em: http://www.abralic.org.br/anais/arquivos/2016_1491523265.pdf. Acesso em: 08 de out. de 2019.

FERRER, Eliete. 68 a geração que queria mudar o mundo: relatos. Org.: Eliete Ferrer. Brasília: Ministério da Justiça, Comissão de Anistia, 2011.

FOUCAULT, Michel. O corpo utópico, as heterotopias. Tradução de Salma Tannus Muchall. São Paulo: n-1 Edições, 2013.

FOUCAULT, Michel. Microfísica do poder. Rio de Janeiro: Graal, 2000.

GRECCO, Gabriela de Lima. História e literatura: entre narrativas literárias e históricas, uma análise através do conceito de representação. Revista Brasileira de História \& Ciências Sociais, Vol. 6, $\mathrm{N}^{\mathrm{o}}$ 11, Julho de 2014. Disponível em: https://www.rbhcs.com/rbhcs/article/view/201/195. Acesso em: 08 de out. de 2019.

HANSEN, João Adolfo. Aula Magna. Dinamarca: Zazie Edições. Pequena Biblioteca de Ensaios. 2019. Disponível em:http://www.zazie.com.br/pequena-biblioteca-de-ensaios. Acesso em: 10 de ago. de 2019.

HOLLANDA, Heloísa Buarque de. Impressões de viagem: CPC, vanguarda e desbunde 1960/1970. Rio de Janeiro: Aeroplano, 2004.

HOOPER, Silvana Seabra. Geração e Juventude: O debate sobre a geração AI-5. Projeto História, São Paulo, v.59, p.337-362, Abri.-Jul. 2017. Disponível em: https://revistas.pucsp.br/revph/article/view/25315/23452. Acesso em: 08 de out. de 2019.

JÚNIOR, Márcio Meirelles Gouveia. Apresentação: Uma nova tradução de Utopia. In: MORE, T. (Ed.). Utopia. Belo Horizonte: Editora Autêntica, 2017.

MATOS, Andityas Soares de Moura Costa. Posfácio. In: MORE, T. (Ed.). Utopia. Belo Horizonte: Editora Autêntica, 2017.

MORE, Thomas. Utopia. Belo Horizonte: Editora Autêntica, 2017.

NETO, Torquato. Torquatália: Do lado de dentro. (Org.: Paulo Roberto Pires) Rio de Janeiro: Rocco, 2004a.

NETO, Torquato. Torquatália: Geléia Geral. (Org.: Paulo Roberto Pires) Rio de Janeiro: Rocco, 2004b.

ORTIZ, Renato. O Popular e o Nacional. In: ORTIZ, R. A Moderna Tradição Brasileira. 5. ed. São Paulo: Brasiliense, 2001. 
PIRES, André Monteiro Guimarães Dias. A ruptura do escorpião: ensaio sobre Torquato Neto e o mito da marginalidade. 1. ed., São Paulo: Cone Sul, 2001. 111p.

PIRES, Paulo Roberto. Introdução: jornal/geléia. In: NETO, Torquato. Torquatália: Geléia Geral. (Org.: Paulo Roberto Pires) Rio de Janeiro: Rocco, 2004b. p.7-23.

RIDENTI, Marcelo. O fantasma da revolução brasileira. São Paulo: UNESP, 2010.

VELHO, Gilberto. Vanguarda e Desvio in VELHO, Gilberto (org.) Arte e Sociedade. Rio de Janeiro: Zahar Editores. 1977, p. 27-38.

XAVIER, Ismail. Alegorias do Subdesenvolvimento: Cinema Novo, Tropicalismo, Cinema Marginal. São Paulo: Brasiliense, 1993. 